\title{
NONLINEAR DYNAMICS OF STRUCTURES: PROJECTS, TESTS, DAMPING, DAMAGES AND THEIR DIAGNOSTICS
}

\author{
VLADIMIR KULYABKO \\ Dr. Sci., Prof. of "Prydiprovska State Academy of Civil Engineering and Architecture” Dnipro, \\ Ukraine \\ 49600, Ukraine, Dnipro, Chernyshevskoho str., 24a. \\ vvkulyabko@gmail.com
}

Key words: dynamic calculations and models of buildings and structures, nonlinearity of elastic and dissipative characteristics, frequencies and forms of natural vibrations, interaction of the bridge structure with transport.

Abstract. The paper considers the features of nonlinear modeling of problems of dynamics of structures at different stages: design, testing and operation. Recommendations are given for nonlinear dynamic calculations and dynamic diagnostics (certification, identification of structural defects, etc.).

\section{INTRODUCTION}

In each difficult problem (namely, these are the problems of nonlinear dynamics) it is useful to create alternative ways to solve it. For example, in construction design, there are complex structures (or their individual subsystems) operated in complex engineeringgeological, climatic, operational, etc. conditions. In this case, sometimes the Customer of the object either entrusts the work to two or three organizations, or requires obtaining results, for example, calculations by different methods for two or three computer software systems. In such cases, the use of a broad alternative and mutual checks is implied. If the results are close, then a good test of the methods has occurred. If the discrepancies are significant, the expert group checks the main stages and either finds a technical error in the approaches of one of the directions, or begins to compare the essence of the algorithms, identifies and applies the most modern and reliable way.

The article refers primarily to the design of structures. (Although a little less, a special method will be proposed - the formation of the essence of the object's shape at an even earlier stage).

If an object is schematically represented with all dynamic influences on its structures (Fig. 1 ), then it is possible to collect tasks of the same type in conditional blocks.

Block of external dynamic loads (underground, ground and air).

Block of internal dynamic influences (from dynamic machines and equipment installed at the facility, from pedestrians, etc.).

And we can also add, according to the scheme, at least three blocks of interaction of the structures of the structure with the environments:

- with a wind flow (here unexpected aerodynamic effects may occur with each new type of object);

- with complex bases (including three types of seismic: natural, industrial, urban); 
- with traffic and pedestrian flows (the diagram fig. 1 shows three options for moving vehicles).

All these loads must be constantly investigated by specialists, measured using the latest instrumental controls and corrected, including new methods of calculating them.

The next step to improve the quality of the project of the object is to draw up an adequate nonlinear computational model for each of these described tasks, the parameters of which must be determined and refined in special field tests of analogue objects, as well as in wind tunnels and dynamics laboratories!
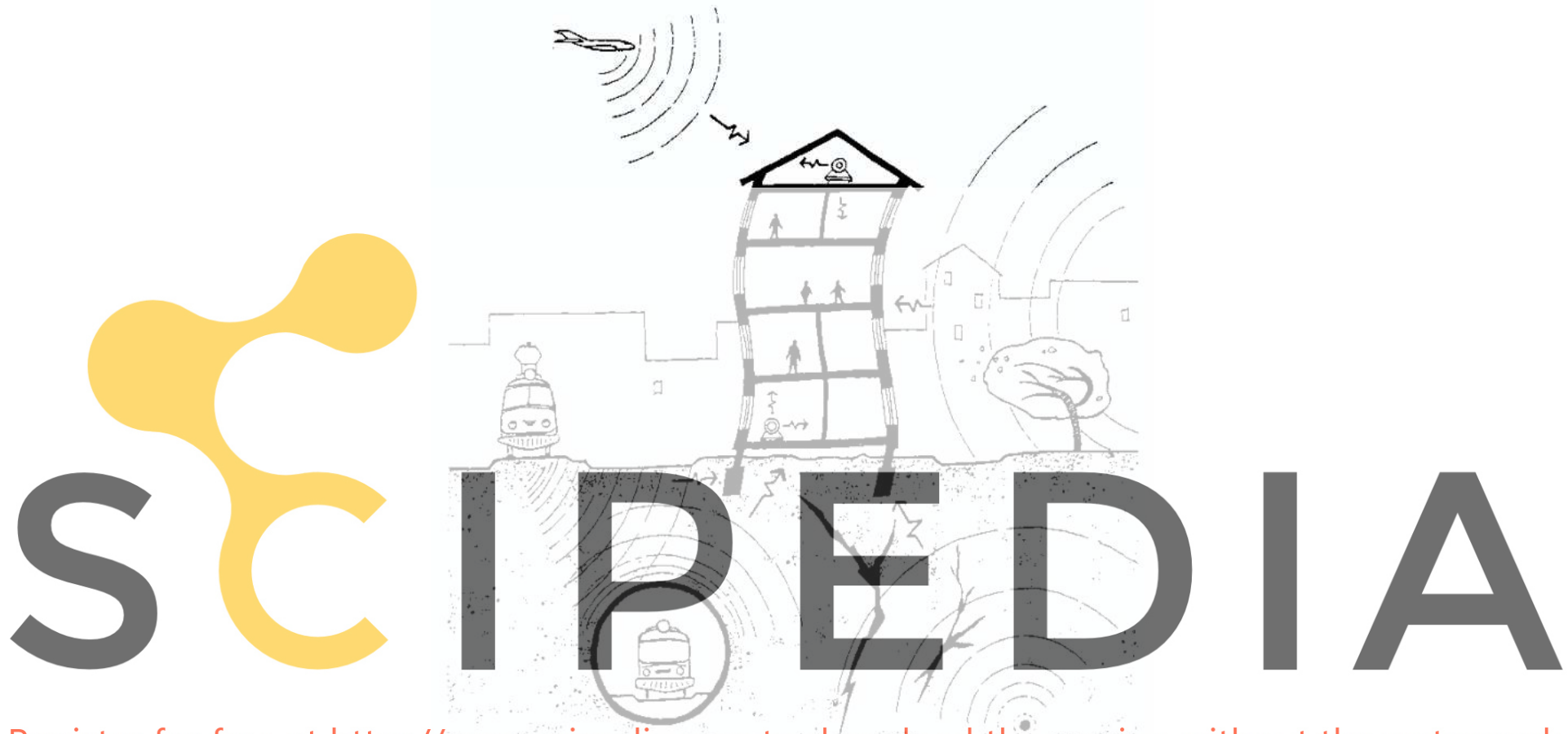

Register for free at https//www.scipedia.com to download the version without the watermark

Figure 1: Diagram of dynamic loads and effects on the structure

\section{RESEARCH GOAL}

The purpose of this work is to find correct, but relatively simple, ways of modeling complex problems of nonlinear dynamics of buildings and structures. To prove the reliability of the basic properties (inertial and elastic-dissipative) and parameters of the accepted nonlinear model, it is also allowed to use linear analogs with the analysis of frequencies and natural vibration modes with the usual use of FEM with a user-friendly computer software systems. This formulation will make it possible to exclude serious errors and more clearly analyze the effect of nonlinearities on the results.

In connection with the emergence of numerous problems of nonlinear dynamics at enterprises, universities and research institutes of Ukraine, as well as in the development of the world famous schools of structural dynamics, V.A. Lazaryan, M.K. Yangel, V.I. Mossakovsky and others, in 1978 there was created (on a voluntary basis) a group of people wishing to research such problems. This group of students and scientists from universities in several cities of Ukraine was named "RESONANCE". During 43 years of work in a group, 3 people defended doctoral dissertations and about seven defended their $\mathrm{PhD}$ theses. 
In this article, the author also mentions some results obtained together with his former graduate students: Igor Davydov (bridge and transport, defending in 2000), Vyacheslav Chaban (experiments, Monument, 2004), Denis Yaroshenko (damping vibrations, 2014), Andrey Makarov (overhead loading cranes, 2015). More detailed information and literature reviews (so as not to clutter up the list of sources in this article) can be found in the corresponding dissertation materials and scientific reports of PGASA.

\section{RESEARCH METHODS}

Currently, the most popular is the construction of only linear dynamic models of buildings and structures using a computer software system based on the finite element method (FEM). This approach, firstly, relieves the user of the responsibility for ignoring all four known groups of nonlinearities in dynamic tasks:

- physical (dry friction forces $\mathbf{H}$, inelastic deformations, etc.; the top row of graphs in fig. 2 shows the dependence of the force $\mathbf{H}$ on displacement a, speed a $\boldsymbol{\omega}$ and time $\mathbf{t}$ - for two dampers such as sheet and wedge springs);

- geometric (taking into account the refined work of the section, points of the entire model, etc.);

- structural (closing and opening gaps, breaking ties and restoring in new nodes);

genetic (the influence of the history of the structure: conditions of manufacture and transportation, object fires, etc.).
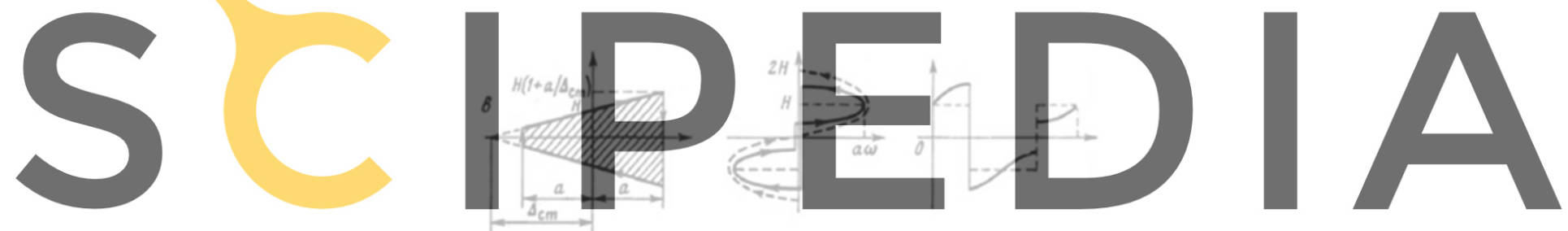

Register for free at https//www.scipedia.com to download the version without the watermark
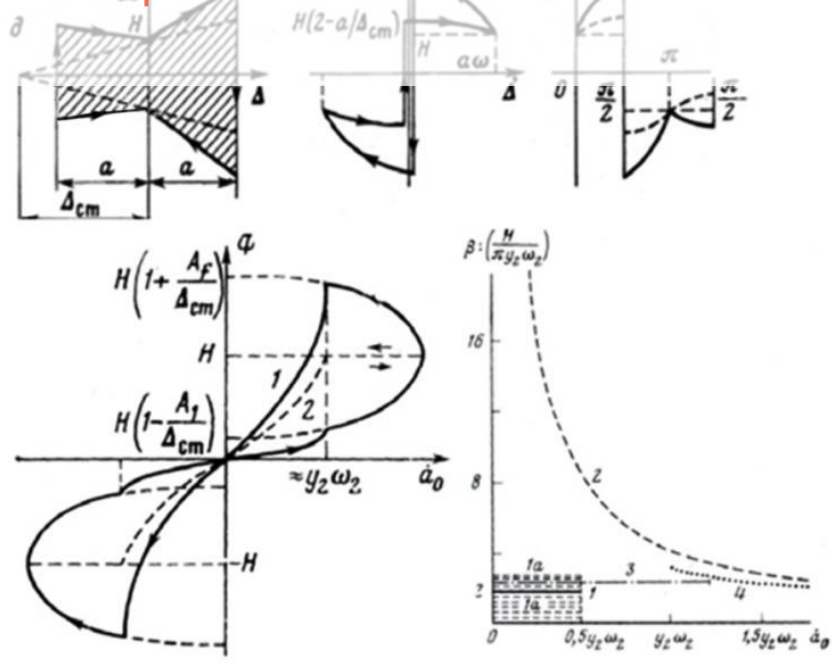

Figure 2: Nonlinear characteristics of variants of dry friction forces at various vibrations 
And, secondly, with the help of a computer software systems the problem of statics is most often solved separately (dead weight, etc.) and separately - dynamics and the results are added as standard. But this "principle of superposition" for nonlinear systems is not applicable and in this case the sum of one common joint solution may differ several times. For example, in the laboratory, we studied the effect of vibration of a unit (with a package of sheets tightened with high-strength bolts) on the coefficient of friction "steel on steel".

It turned out that without vibration the coefficient was 0.35 . And with a certain vibration of the node, for example, it decreased by an order of magnitude (0.03), which is explained by such a specific phenomenon as "vibration smoothing".

It is convenient to compare with fig. 2 the lower left graph of the change in the force $\boldsymbol{H}$ from the high-frequency speed $\boldsymbol{a}_{2} \boldsymbol{\omega}_{2}$ and a similar graph at the top, without vibration. Let's note that dry friction forces are one of the types of physical nonlinearity that is present in the nodes and joints of many structures, in mechanisms, in most types of soil bases, etc.

Thus, in nonlinear dynamics, it is impossible to apply convenient but incorrect linear methods such as FEM and the corresponding computer software systems, but it is necessary to accept correct models with nonlinearity parameters obtained from experiments under normal operating conditions of a particular object or subsystem. It is very useful to apply "sets of properties": variable or constant in time, elastic, dissipative, inertial, etc., in particular, for modeling vibration compaction of mixtures.

Another convenient form of introducing nonlinearities into the calculations of rod systems is the method of straight limes (sections of the rod are divided into straight line segments

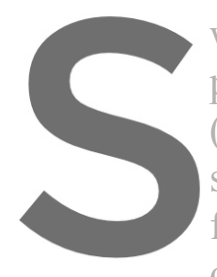
with equivalent moment possible to construct var (switched on and off stops, etc. By the way, freedom, it's better to only to an oscillator, to "diagrams of dynamic co
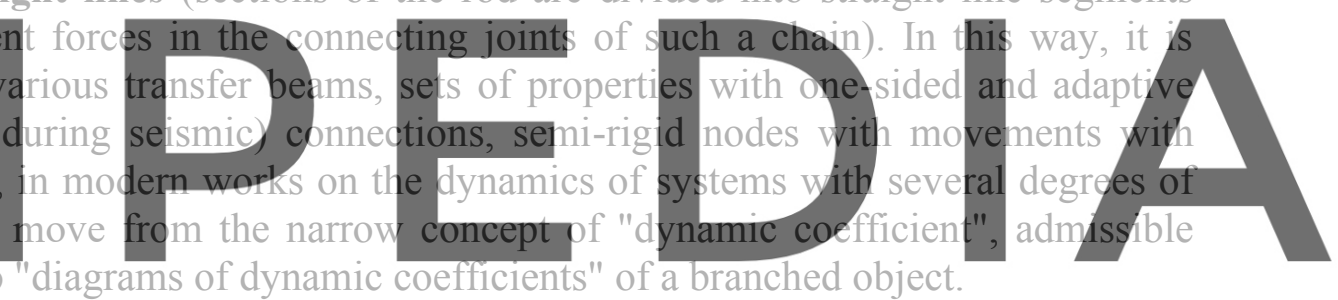

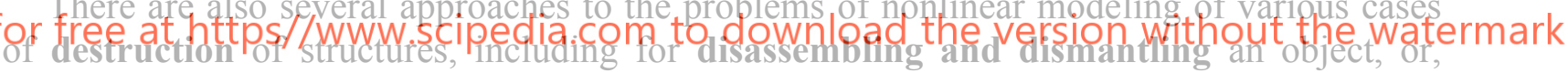

conversely, for strengthening its fragment from possible "avalanche-like" consequences. The general principles of location on the spectra of natural frequencies of "zones of their concentration" for frame and multi-span continuous beam structures are also found. This is due to the fact that in real problems you have to create a variety of models: they can be nonlinear, discrete, multi-element, etc.

Further, according to the algorithms of the proposed methods, systems of nonlinear differential equations of motion are compiled taking into account the boundary and initial (in time) conditions. And sometimes it's necessary to take into account the joint solutions of differential and algebraic equations, testing of their linear parts by linear solutions of frequencies and modes of natural vibrations (FEM on computer software systems).

Fig. 3 shows examples of some of the most complex discrete static-dynamic models - the interaction of bridge structures (suspension at the top, beam at the bottom) with a train of freight cars moving on a heterogeneous layered base under a rail-sleeper lattice, and loaded ones - long, freely oscillating weights. It is noticeable that the supporting frames of the lower model of the railway carriage and the beam bridge are modeled according to the method of straight lines, and the suspension in the form of sets $-\boldsymbol{K}$ is double (on locomotive bogies) and single spring suspension - on a freight car, next to the locomotive. 

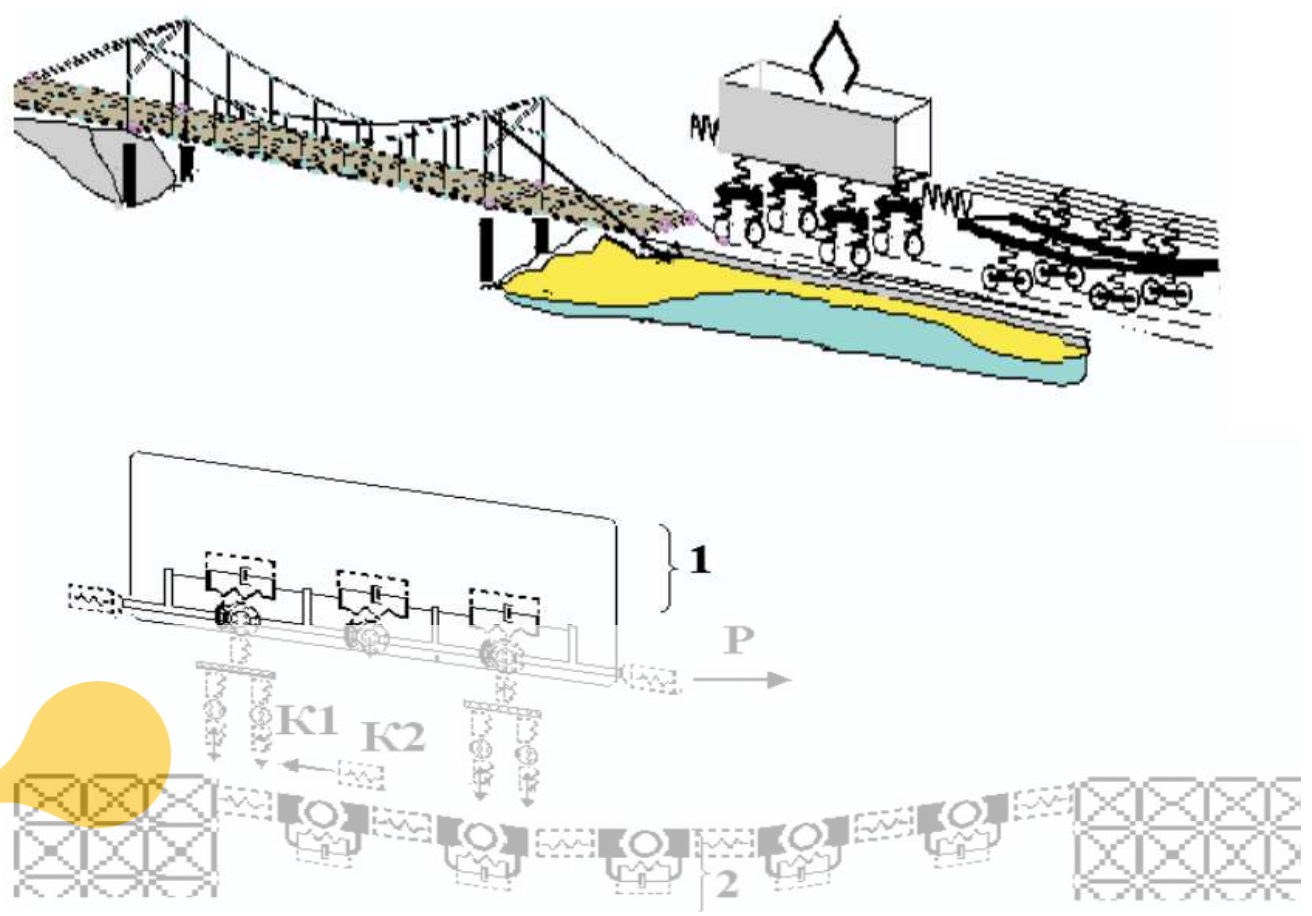

Figure 3: Discrete models of bridges, foundations, locomotive, wagon and cargo
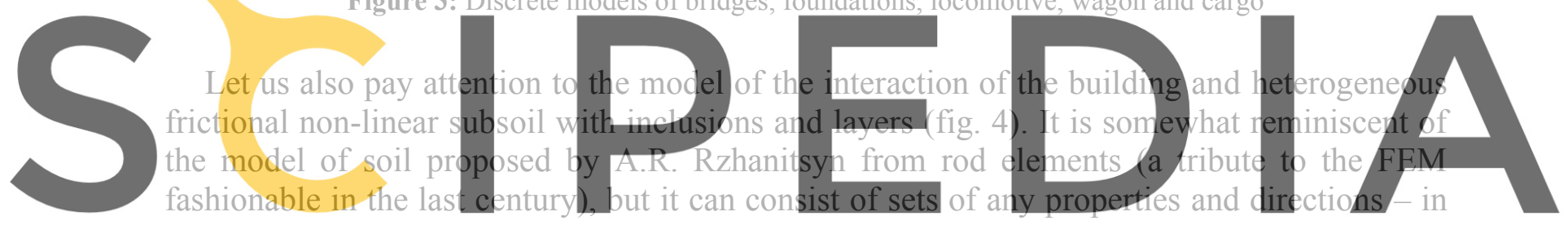

accordance with the data of specific engineering-geological studies of soil sections and wells.

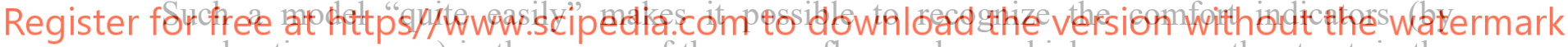
acceleration sensors) in the rooms of the upper floors when vehicles pass on the street, in the subway, etc. For example, scientists from Politechnika Krakowska have been engaged for many years in similar tasks of protecting the historical monuments and churches. Regulatory materials for such tasks have also been released.

So, the approach includes such very multi-element subsystems, but on the other hand it allows observing any processes and parameters on the graphs of their changes in the time domain - on vibrograms of accelerations, displacements, dynamic stresses, their sums with static stresses! How to get these calculated vibrograms? The research methodology presupposes the numerical integration of the obtained systems of equations either almost manually, using the Runge-Kutta 4th order method, or using the services such as Maple, MathCAD, etc.

To speed up the proposed research methods, a certain sequence of solving a large problem can be recommended. For example, do not chase after a huge number of elements (as happens in the almost automatically generated spatial models of "erroneous in dynamics FEM"), but first study a simplified flat nonlinear static-dynamic model. Based on these results and testing the linear part, it is necessary to make a decision on the need for further refinement of the nonlinear model on conducting targeted experiments, etc. 


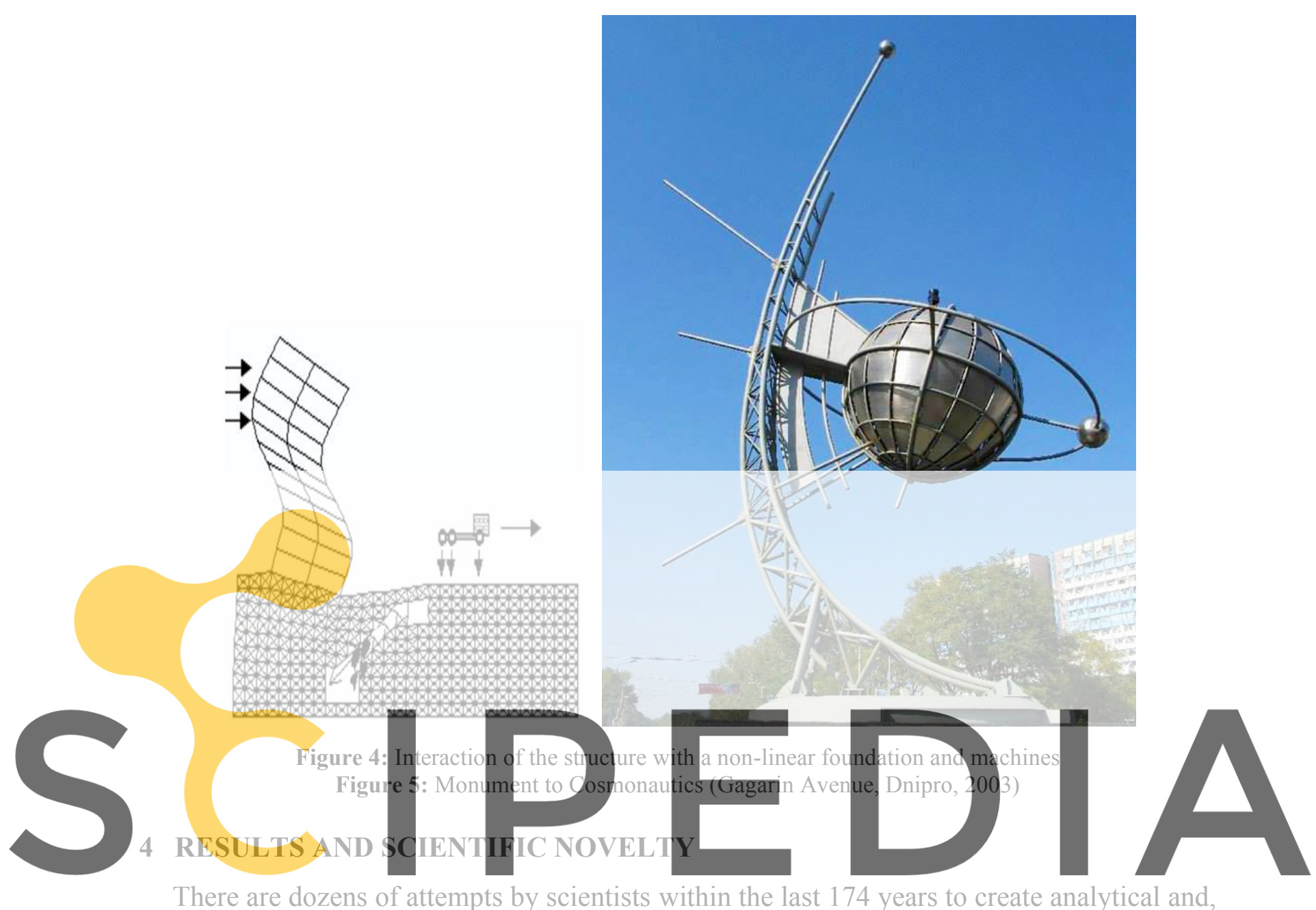

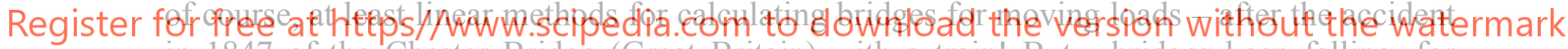
in 1847 of the Chester Bridge (Great Britain) with a train! But... bridges keep falling, for example, in August 2018, the accident of a highway multi-span bridge in Genoa (Italy).

The most progressive innovation of this paper can be considered a specific proposal for modeling the nonlinear interaction of bridge structures with moving vehicles. By analogy with the nonlinear models described above, the specific example (fig. 6) shows a model of a flat frame with three spans and a height of 20 meters. A column of cars can move along the frame in one or both directions at any speeds, intervals and axial loads. In the example, three loaded (30 tons each) modern Tatra vehicles are moving from left to right. The solutions are given in the form of vibrograms of the vertical displacements of the middle sections $Z_{i}$ and the horizontal deflection of the entire horizontal rod of the $\boldsymbol{X}$ frame. (It is assumed that the schematic and instrumental generalization and patenting of the method for ensuring the trouble-free operation of the facility).

Similar tasks are solved according to similar models and for the passage of vehicles over random roughness, during landing and takeoff of an aircraft on the elastic base of the runway structure, when a several vehicles move along a road with various types of road construction.

For example, the following possibilities of the proposed methods are very important in practice. The method of dynamic shaping (MDS) of buildings and structures mentioned at the beginning of the article has made it possible to quickly assign all sections and 
configurations of spatial trusses of the Monument (fig. 5) of variable sizes at the pre-design stage only for the three lowest frequencies and forms of natural vibrations. After that, for the selected design option, a standard calculation was made once for all combinations of loads.

This method can be called "the outstretched hand of an engineer to an architect constructor!" It seemed to be "supported" by the recently released ISO recommendations on the frequencies of the three lowest natural forms of tall buildings with a rectangular plan.

The results of tests and calculations of 163 best buildings in the world were processed: graphs of the dependence of the frequency of each shape on the height of a particular building were built. And simple formulas were obtained for these three lowest frequencies in Hz: a fraction, in the denominator of which the height of the building is in meters, and in the numerators, respectively, $46 ; 58 ; 72$.

The method of dynamic construction (MDC) allows not only estimate the frequencies and modes of natural vibrations, like the MDS, but also adds important analysis with estimates of the amplitudes of forced vibrations. Using MDC, it is possible not only to design the entire structure, but also to find ways to reduce the level of oscillations and vibrations - by installing absorbers, dynamic vibration dampers (tuned mass dampers). With the help of MDK, we can also determine the rational places and directions of installation of all kinds of damping devices, calculate the conditions for their frequency tuning for different types and frequencies of dynamic effects on the object.

Finally, the proposed method of dynamic diagnostics (MDD) is very diverse, it includes the presence of dymamic passports (DP) at all stages of the object's existence, in particular, -

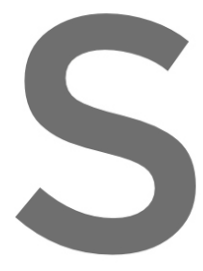
from the project ("project D several "ongoing DPs" complex repairs, recons
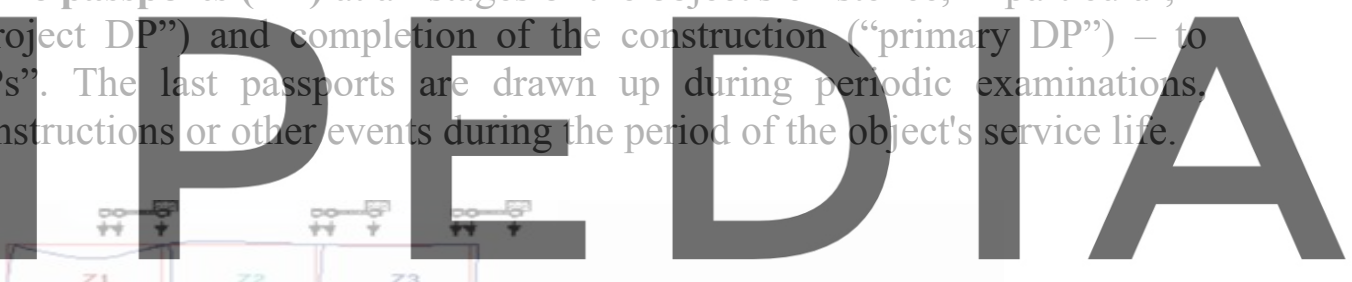

Register for free at https//www.scipedia.com to download the version without the watermark

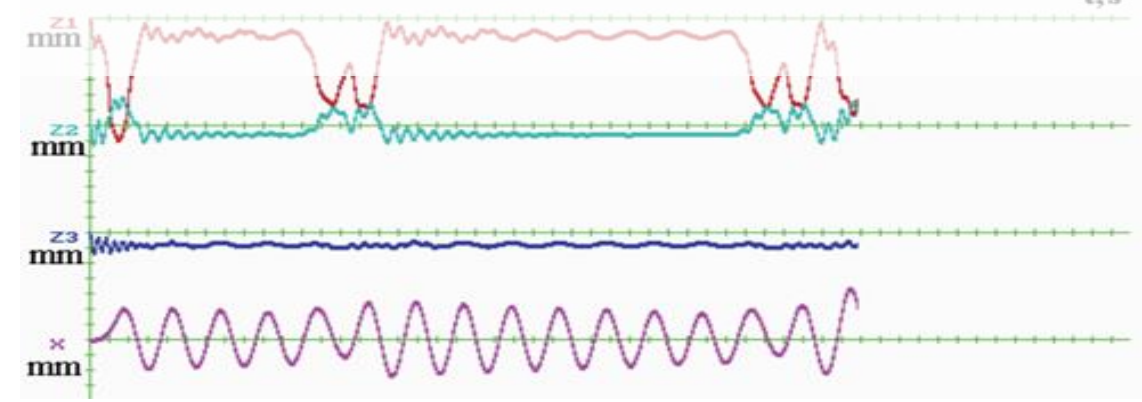

Figure 6: Vibrograms of vertical $\mathrm{Z}$ and horizontal $\mathrm{X}$ displacements of a three-span overpass frame when a column of thirty-ton trucks is moving along it

In addition, the joint use of MDD with MDK will first make it possible to draw up a current dynamic passport based on the results of current dynamic tests. And then, having a pre-calculated or instrumented "Album of the influence of various damages on the frequencies and modes of natural vibrations", we can compare the results. It is especially easy to find the damage that breaks symmetric vibration modes. It is convenient for engineers to propose in the same "Album", for example, and ways to eliminate the same type of damage, 
which will reduce the time of inspections and downtime of structures and machines. (The methods and technologies described above are being finalized and prepared for their patenting).

Let us recall that in order to obtain adequate results of calculations based on complex theoretical models, it is important to correctly carry out field experimental measurements with an estimate of the dissipation of both subsystems and the entire structure. In different computer software systems, in different years, methods have been proposed for imposing the so-called "proportional friction" on the dynamic calculation algorithm - either proportionally to the flexural stiffness, or to the values of the masses and their location on the object.

And as a result, in real combined (sometimes they say "composite") structures made of different materials on different forms of freely damped oscillations, different indicators of dissipation were obtained - at different amplitudes and frequencies, (fig. 7) - some of the upper floors are made of metal, the lower ones are made of reinforced concrete, the base is soil with the highest coefficient of inelastic resistance and a logarithmic decrement of vibrations. This is the greatest difficulty for correct dynamic calculations of strength, endurance, etc.
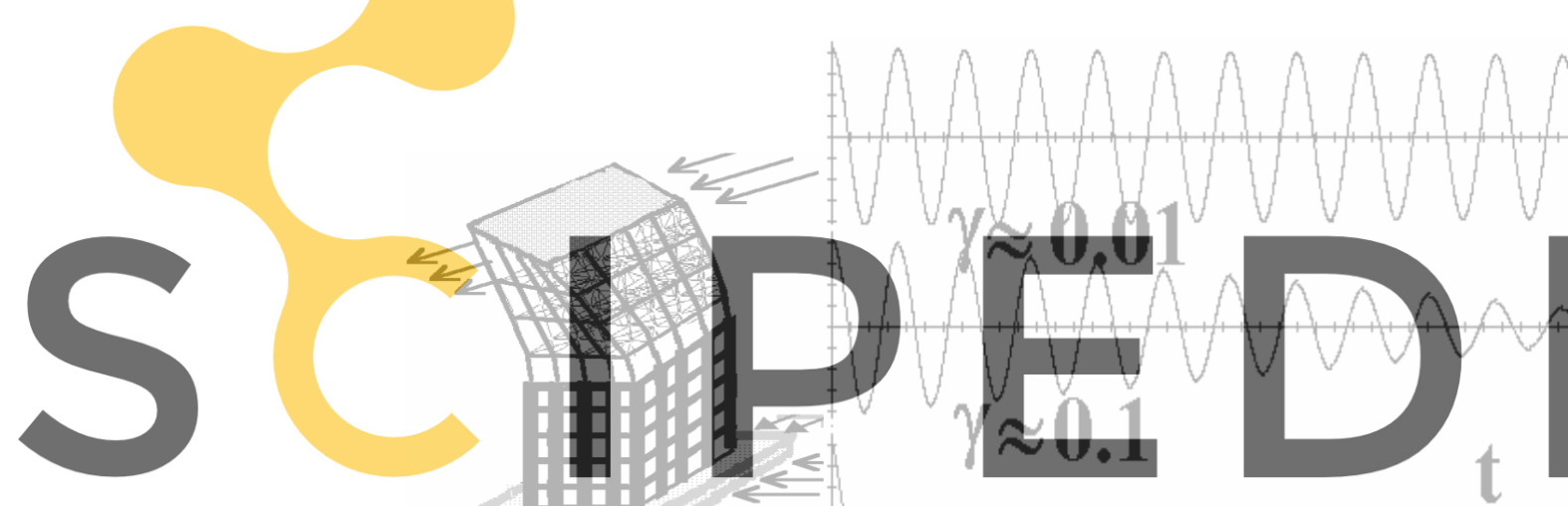

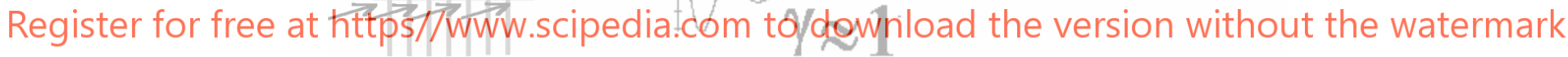

Figure 7: Dissipation of parts of the combined structure made of different materials

In conclusion of these studies, we will illustrate the work with MDD on models and experiments with a "large steel object" - a large-span bridge loading crane. Such cranes with the length of the spatial system with sled beams - about 140-150 meters and the metal mass of about 700 tons can cost the purchasing company about $\$ 7,000$.

The fig. 8 schematically shows lattice and tubular cranes. The fig. 9 shows an example of a dynamic passport for the second of them, and the fig. 10 - three lower modes of natural vibrations for both designs.

And, as a result of the analysis of the level of development of nonlinear dynamics, we will indicate for discussion several possible directions for further research (primarily in relation to Ukraine). Obviously, it is advisable to maximally raise the level and regular update of regulatory documents and engineering manuals on all practical issues and sections of the dynamics of structures. 


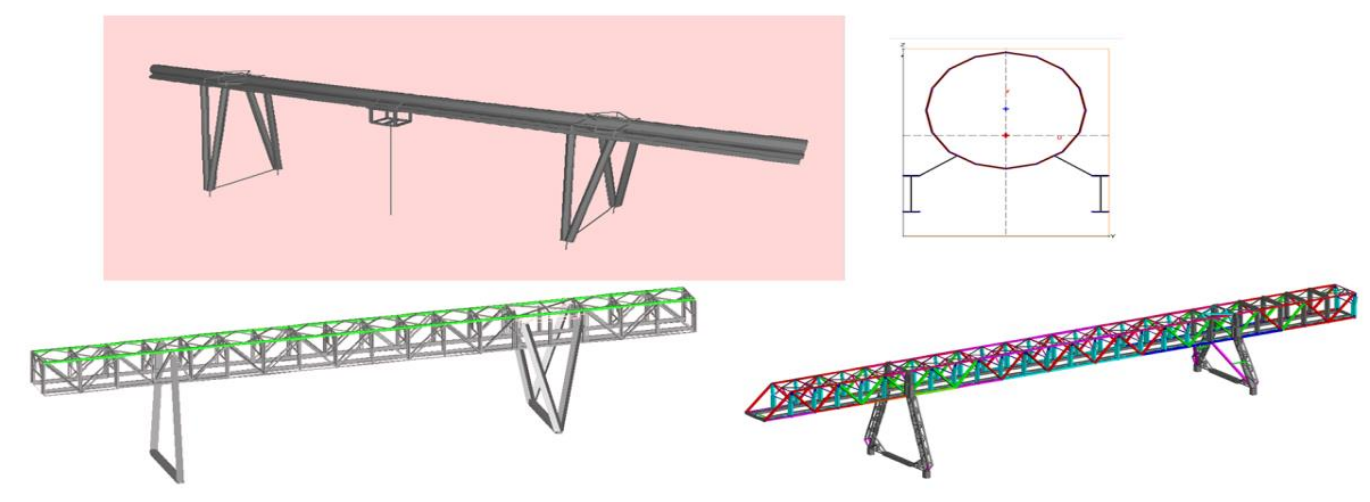

Figure 8: Diagrams of bridge cranes of tubular and lattice type

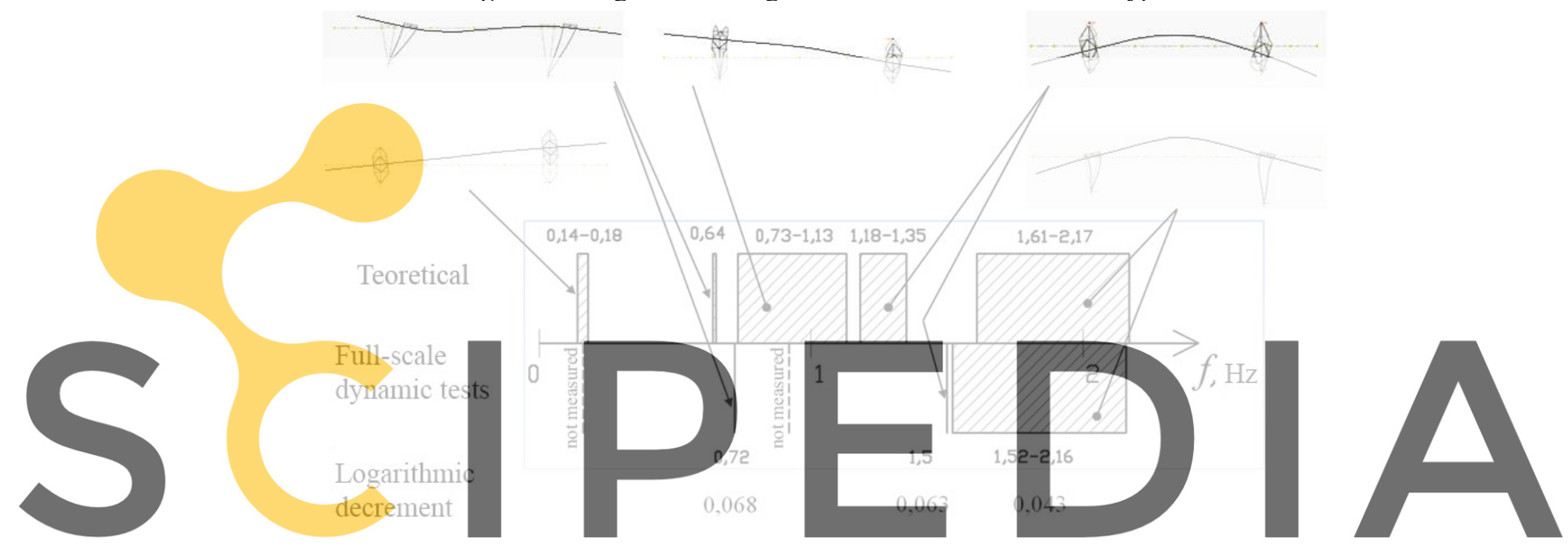

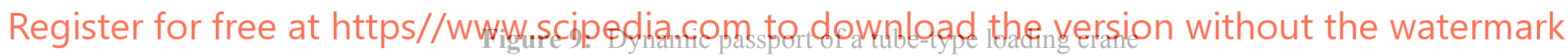

$1 f 0,65 \mathrm{~Hz}$

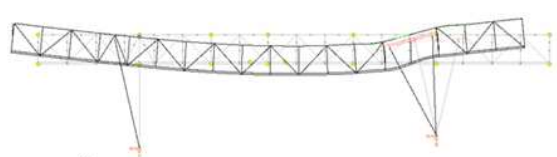

$2 f 0,85 \mathrm{~Hz}$

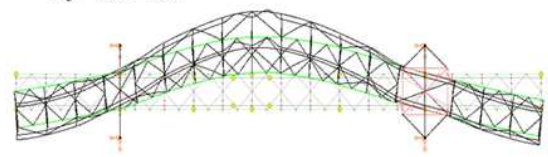

$3 f 1,7 \mathrm{~Hz}$

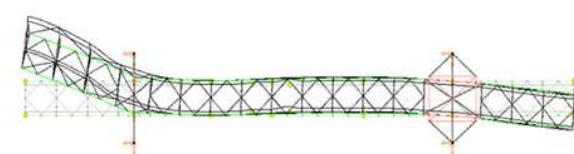

$0,64 \mathrm{~Hz}$

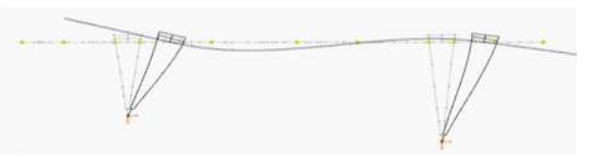

$0,77 \mathrm{~Hz}$

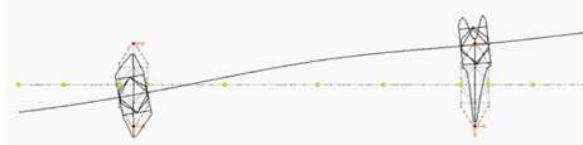

$1,26 \mathrm{~Hz}$

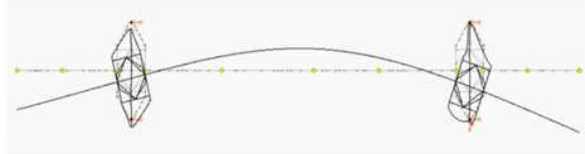

Figure 10: Low frequencies and modes of natural vibrations of lattice (left) and tubular (right) loading cranes 
It is also possible to set up centralized Structural Dynamics Laboratories (Hubs), which will lead the work on the creation of new software and instrumentation for dynamic problems, and audit of enterprises, and certification of testers and teachers in dynamics courses for engineers. It is advisable to equip in such a Hub schools for teaching nonlinear calculations, conducting complex (laboratory, computer-virtual and field) tests, compiling dynamic passports.

Practically important are not only the proposed methods of MDS, MDK, MDD, but also the tasks of working on computer simulators, on vibration protection, vibration isolation, reducing the level of dynamic stresses, etc. Many countries desperately need specialists to diagnose and assess the pre-emergency state of thousands of bridges, and close cooperation is possible here.

Such cooperation is also possible in joint research to ensure vibration comfort (quality of human life), vibroecology, biomechanics, etc.

\section{CONCLUSIONS}

The report shows a significant effect of nonlinearities on dynamic processes in structures: on displacements, accelerations and on dynamic stresses in structures. For the trouble-free operation of buildings and structures, such processes should be calculated using refined models and, if possible, their amplitudes and harmful effects on people, devices and structures should be reduced.

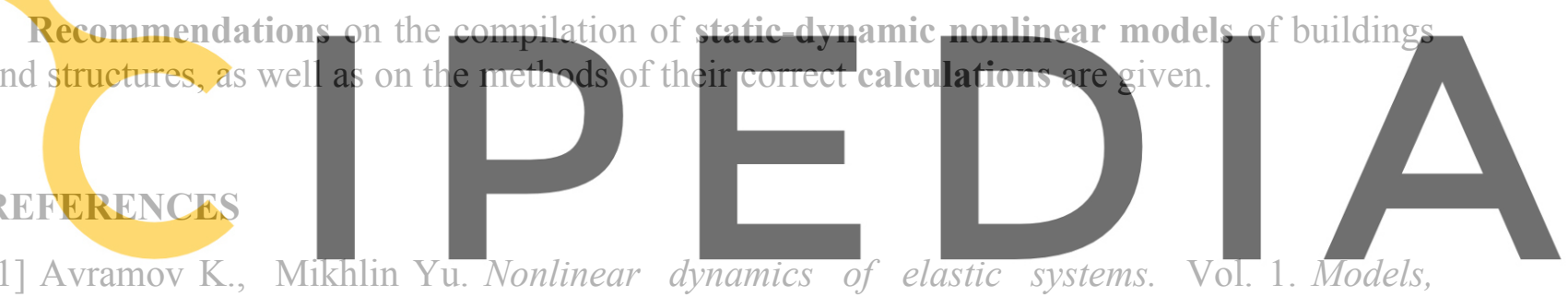

[1] Avramov K., Mikhlin Yu. Nonlinear dynamics of elastic systems. Vor.

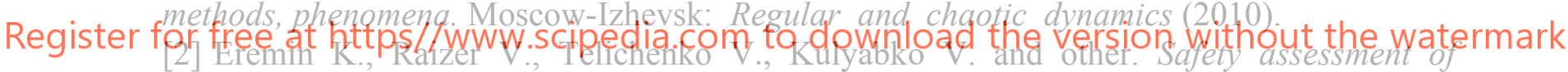
existing buildings and structures / Monography. - Stockholm, Sweden: FSV Construction, (2016) - $268 \mathrm{p}$.

[3] Ivovich V., Pokrovsky L. Dynamic analysis of suspension coatings. Moscow: Stroyizdat; (1989).

[4] Kadisov G., Dynamic and Stability of Structures. Moscow: ABI Publishing House; (2007).

[5] Karnovsky I., Lebed E. Theory of vibration protection. Switzerland, Cham: Springer International Publishing AG; (2016).

[6] Kazakevitch M. Wind safety of the structures. Theory and practice. Moscow: "August Borg" Typography; (2015).

[7] Kulyabko V. Dynamics of structures - past, present and future (Part 1). Saarbruken: LAP: LAMBERT Academic Publishing; (2014).

[8] Kulyabko V., Babenko M. 2.8. Synergy of vibroecologists, programmers, inventors and testers of buildings and structures under the evaluation of the impact of the dynamics of structures / S 94 Sustainable housing and human settlement: Monograph / Under the general editorship Savytskyi M. / Dnipro - Bratislava: SHEE "Prydniprovska State Acad. of Civil 
Engineering and Architecture" - Slovak University of Technology in Bratislava, (2018), (263 p., ISBN 978-966-323-182-2), p.108-115.

[9] Kulyabko V., Davydov I. Variants of the complex dynamic phenomena simulation and analysis of transport structures with moving loading. Proceeding of the 2 nd Intern. Conf. On Dynamics of Civil Ing. And Transport Structures and Wind Engineering / University of Zilina. Slovak Republic, May 19-22, (2003), p.148-151.

[10] Kulyabko V., Davydov I., Chaban V. About problems outlooks of creation of international experimental lab of dynamics. Proc. of the 2nd Intern. Conf. On Dynamics of Civil Ing. And Transport Structures and Wind Engineering / University of Zilina. Slovak Republic, May 19-22, (2003), p.258-261.

[11] Kulyabko V., Davydov I. Laboratory of Dynamics and Diagnostics of Constructions / Archive of Civil Engineering / Polish Academy of Sciences, Institute of Fundamental Technological Research. Vol.49, №3 (2003), Warsaw, p.295-320.

[12] Kulyabko V., Macarow A., Nechitailo O., Yaroshenko D. Structure dynamics: calculations, designing, diagnostic tests and nonlinear damping / Harvard Journal of Fundamental and Applied Studies. - Harvard University Press, (2015), №1(7), p. 520-530.

[13] Kulyabko V., Chaban V., Makarov A., Yaroshenko D. Taking account of nonlinear properties of subsystems in problems of dynamic interaction of structures with loads, bases and flows / Nonlinear Dynamics - 2016: Proceedings of 5th International Conference (September 27-30, 2016) / National Technical University "Kharkov Polytechnic Institute" at al. Kharkov, (2016), p.125-132.

[14] Kulyabko V., Chaban V. Oscillations and loading of flexible elements in a composition cable-stayed and suspension structures. Proc. of the 2nd Intern. Conf. On Dynamics of Civil Ing. And Transport Structures and Wind Engineering / University of Zilina. Slovak Republic, May 19-22, (2003), p.254-257.

[15] Kulyabko V., Chaban V. The study static and dynamic performance of suspension strands finite stiffness. Theoretical foundations of civil engineering, (2002), Vol. 2. - p.740745.

[16] Makarov A., Yaroshenko D. inventors. Tuned Mass Damper for crane-loader. Ukraine patent 99209, F 16 F 7/10. (2015), May 25.

[17] Minregion of Ukraine. DBN V.1.1-12:2014. Construction in seismic regions of Ukraine. Kyiv: Public Institution "Ukrarhbudinform"; (2014).

[18] Perelmuter A., Kabancev O. Analysis of structures with varying design model. Moscow: ScadSoft Publishing, ABI Publishing House; (2015).

[19] Shimanovsky V. Suspension system (design and calculation of finite rigidity strings). Kiev: Budivelnik; (1984). 